\title{
The Color Arrangement of Working Clothes for Visibility in Machine Industrial Work Site ${ }^{+}$
}

\author{
Park Hyewon \\ Professor, Dept. of Clothing \& Textiles, Changwon National University
}

\begin{abstract}
This study is about the evaluation of the color arrangements of working clothes that are harmonized with working environment and assist in the protection of workers in industrial sites. This study attempted color arrangement design with the intention of giving order to the colors of working environment and working clothes so as to help improve the safety of work and the management aspects including human resource management, efficiency improvement, and the practice of business ethics.

The study method consisted of literature research, empirical research, and evaluation research. The literature research performed theoretical examination about colors, industrial safety, and visibility. Three actual outdoor work sites in the machine industry were chosen and pictures were taken at 20-30 m from workers. The background colors of the work environment of each work site and the colors of the working clothes that were actually worn were analyzed through color values measured with a color-difference meter(CR-400).

As a result, it was found that between value and chroma which affect visibility, color arrangement based on differences in chroma could be a greater influence than color arrangement based on differences in value. The results of this study could assist the integration of color schemes among working environment colors, people and working clothes by suggesting color arrangements with improved visibility that are applicable to the working clothes of domestic machine manufacturers that are playing a pivotal role in domestic industries and by presenting appropriate guidelines.
\end{abstract}

Key Words : High Visibility, Color Arrangement of Working Clothes, Similar Color Arrangement

\section{Introduction}

In-depth discussions have been conducted in various academic fields to raise awareness of the society in general about safety in industrial sites. In order to raise awareness about industrial safety, standardization, certification, systematization, educationalization, and consideration

+ This work was supported by National Research Foundation of Korea(NRF) grant funded by the Korea government(MEST)(No.2012R1A1B5003705).

Corresponding author: Park Hyewon, Tel. +82-55-213-3494, Fax. +82-55-213-2724

E-mail: hwpark@changwon.ac.kr 
of learner's level are more important than general conditions. It has been pointed out that before a work environment in industries can be actualized, the requirements for general on-site safety must be systematized and form organic relations. ${ }^{1)}$ In a related case study, safety accidents about erroneous motions were classified by the aspects of perception, behavior, judgment, and emotion. Detailed countermeasures were established for each element and applied to workers, and the effects of the countermeasures were evaluated after performing them. As a result, 'forgetting' and 'not looking' were found to be the greatest factors, suggesting that workers were weak in visual perception. ${ }^{2)}$ The visual perception of people is realized in the relations between colors, and in living environment, single colors are rarely used.

The first vehicle for securing the safety of workers in industrial sites would be the working clothes of workers. Therefore, visibility which plays a key function in visual perception or identification of workers through colors is one of the essential functions of working clothes. Even though active studies on working clothes have been conducted with regard to motion functionality in ergonomic and composition areas and the material characteristics of functional working clothes, there were no studies that investigated and evaluated color arrangements of working clothes in relation to industrial safety.

This study is about the evaluation of the color arrangements of working clothes that are harmonized with working environment and assist in the protection of workers in industrial sites. This study attempted color arrangement design with the intention of giving order to the colors of working environment and working clothes so as to help improve the safety of work and the management aspects including human resource management, efficiency improvement, and the practice of business ethics. The environment colors of a workplace influence the physiology, psychology, and mentality of workers, and they act as conditions for the accidents, safety, and work performance of workers. Therefore, the working clothes of workers are a critical issue in the color planning of work environment in industrial complexes, and the environment colors of industrial complexes should be extended to the domain of working clothes. Actually, colors are used in various areas including designs, lighting, and environmental design. As it was argued that more studies are needed for systematic analysis and understanding of the senses and emotional reactions of people caused by colors ${ }^{3 / 4) 5}$ ), studies on colors for communication and information delivery between workers in industrial sites, especially those with dangerousness are most important.

Color harmony refers to giving order to multi-color arrangements with two or more colors. Unlike personal tastes or preferences, it means no contradiction or collision in the application of opposite elements such as unity and change of colors, or order and diversity. In other words, color harmony is to establish and systematize the principles of harmony between different color arrangements by presenting certain orders and laws to the traditional color arrangement methods which are chromatically complex and diverse. ${ }^{6)}$

In previous studies ${ }^{7 / 8)}$, the working clothes and working sites of domestic machine manufacturers were investigated for integrated environment planning, and color reality cases for the harmony and stability of integrated environment were evaluated and analyzed. In the machine industry among the manufacturing industries of 
Korea, Gyeongsangnam-do is playing central role as no. 1 in equipment manufacturing, no. 1 in precision instruments, no. 3 in automobiles, and no. 1 other transportation equipment in terms of production output. ${ }^{9)}$ Thus, this study investigated the color scheme and color arrangement of working clothes that are applicable to the machine industry in Gyeongsangnam-do, selected the working clothes' colors based on them, conducted field experiments through color arrangement simulations and performed evaluations by an expert group.

The results of this study could assist the integration of color schemes among working environment colors, people and working clothes by suggesting color arrangements with improved visibility that are applicable to the working clothes of domestic machine manufacturers that are playing a pivotal role in domestic industries and by presenting appropriate guidelines.

For experimental colors, a similar color arrangement of purple blue and blue was attempted. The basis for this is that purple blue is one of the most frequently used working clothes colors in the domestic machine industry at present, and similar color arrangement has been traditionally known to be harmonious basic color arrangement in their relationship with surrounding working environment colors. Furthermore, in a previous study ${ }^{10)}$, blue color showed a high degree of satisfaction. This also agrees with the finding of a previous study ${ }^{11}$ ) that the blue line colors were appropriate for the building of a safety net that can call the attention of workers through tension and harmony with other colors. For these reasons, purple blue and blue were used in this study. Traditional harmonious color arrangements also include opposite and complementary color arrangements, but similar color arrangement was chosen because due to the nature of working clothes, two-color arrangement with the dominant colors of top and bottom clothes is the basis, and the opposite and complementary color arrangements are used for dominant colors and can give some feeling of fatigue when they are used for working clothes.

\section{Theoretical Background}

Human beings depend on vision for $80 \%$ or more of the information they get through five senses in daily life. ${ }^{12)}$ The colors of the environment surrounding people visually stimulate them who react to the colors which influence their behavior. Environmental colors have psychological implications beyond the one-onone combination of the two words, 'environment' and 'color.' In regard to this, Faber Birren (U.S.A., 1900 1988) said "Environmental colors are indispensable elements for the creation of a controlled environment related to the safety, health, and survival of humans." ${ }^{13)}$ Colors have been widely and practically used to alert people in areas where they may be exposed to dangers. In industrial sites where indifference or monotony can weaken attention and endanger people's lives and bodies, colors are used for rational purposes. The use and application of colors is more important in industrial sites than any other places. Indexing through colors or color separation of the obstacles or dangerous articles in a mechanical environment is a function to selectively use or express tension in order to draw attention to the parts that need be noted. This function is a type of encoding involving color function.

Indexing and color separation can protect 
workers and help the jobs of supervisors in work places and factories. Therefore, the safety effect through colors is to improve safety by preventing dangers while not interfering with activities. That is, the fundamental purpose of securing visibility through the clear vision and attractiveness of colors is to protect and call the attention of workers. Attractiveness refers to the conspicuousness of colors or light due to strong stimulation. For example, warm colors such as red are highly attractive colors. Meanwhile, clear vision refers to good vision from a distance when two colors are contrasted, or conspicuousness due to strong stimulation of the color itself. On the other hand, high visibility can be regarded as good vision from a distance due to the characteristics of colors.

Colors with clear vision must be used to prevent workers from loosening up too much or to remove dangerous elements for the safety of workers. That is, environmental colors in a work place affect the physiology, psychology, and mentality of workers, they act as conditions for the accidents, safety, and job performance of workers. Therefore, because the working clothes of workers are critical issue in the color scheme of work environment in industrial complexes, the environmental colors of industrial complexes that are extended to the domain of working clothes must be planned in an integrated way. In the final analysis, environmental colors are directly related to the survival and safety of human beings and are essential elements for keeping aesthetic values. Thus, environmental colors are a part of the environmental problem related to color use from the sociocultural dimension. ${ }^{14)}$

The achievement of safety through colors is a type of color conditioning. Color conditioning is the functional use of colors or its method to create safe, efficient work environment and comfortable living environment through the active use of the physiological and psychological effects of colors. ${ }^{15)}$ For the origin of color conditioning, it has been reported that in 1925 , a surgeon in a New York hospital complained about eye fatigue due to the white wall in the operation room and the problem was solved when Faber Birren who was color consultant in DuPont changed the color of the wall to blue. ${ }^{16)}$ Since then, continuous efforts for color conditioning have greatly contributed to the improvement of work environment, safety, will to work, and productivity. In particular, working clothes with high visibility reduced dangers and enhanced safety in work places. ${ }^{17)}$

The three elements of color conditioning are clear vision, will to work, and safety and the four requirements of color conditioning are efficiency, safety, comfort, and aesthetics. ${ }^{18)}$ This implies that the use of colors is an essential part of safety.

In 1970, the U.S. government established Occupational Safety and Health Administration (OSHA) and enacted the Occupational Safety and Health Act which required industries to apply specific safety standards. ${ }^{19)}$ For example, road traffic workers who are required to wear highly visible clothes and hats must follow the highest grade of regulations in accordance with the U.S. federal standard (ANSI/ISEA 107-2010: High-visibility safety apparel - unraveled). ANSI/ISEA has three numbered performance classifications for high visibility apparel.

The lowest class 1 applies to workers in warehouses and shopping centers, class 2 applies to truck delivery workers, and the highest class 3 applies to road construction workers, emergency medical technicians, and industrial workers. In this way, the standards are very detailed by the type of work and occupation. ${ }^{20)}$ 
OSHA is also publishing safety standards for special industries such as construction, agriculture, and ocean industries (Department of Labor, 1993). Since 1960s, the color schemes have progressed in the comprehensive and general directions including the characteristics of materials, possibility of contamination, discoloration, age and occupation of workers, beyond the simple concept of fragmentary color conditioning. OSHA has proposed Safety Color Codes for detailed guidance to the clothing and protective gear of workers by body parts as well as the use of reflective materials and fluorescent colors to provide visibility in dangerous environments. ${ }^{21)}$ ANSI has also presented measures about safety vests including examples about the methods of achieving high visibility, adjusting methods, and composing methods. ${ }^{22)}$

The EU established the EN471 standard long time ago which classifies safety requirements into three classes. Unlike the U.S. standard, Class 1 requires the highest safety in working clothes which are high visibility (or $\mathrm{Hi}-\mathrm{Viz}$ ) apparel which is typically worn by railroad or road construction workers. The EU has prepared very detailed standards for these clothes. The standard specifies the width of reflective material strip as $5 \mathrm{~cm}$ and even its area in the working clothes to give the best visibility. These standards provide easy criteria for judgment and automatically provide the standards for actual training of experts, thereby building the infrastructure. ${ }^{23)}$

Korea also has Korean Industrial Standards (KS) about safety vests as working clothes related to visibility. The regulations about safety vests are very detailed including inspection methods, percentage of blending fiber, physical characteristics test method for fabrics, color fastness, color fastness to washing, and dimensional change rate, width of retroreflection material (minimum $50 \mathrm{~mm}$ ), position, and sewing method, chromaticity coordinates and luminance coordinates of fluorescent colors, and reflection coefficient. The material regulations on safety vests and special clothing are also defined in detail. Now we need the classifications of work groups in industrial sites such as those in the U.S. and the EU as well as the establishment of even thought they are not highly dangerous jobs that require absolute visibility such as retro-reflection and fluorescent bands, the workers in the machine manufacturing industry could achieve improved visibility through color arrangement using general working clothes. It is believed that the integrated conditioning of color arrangement of working clothes and the colors of work sites can provide safer work environment. Therefore, it is important to choose the right colors of working clothes for the work sites.

The effects of using the right colors include better feelings, reduced tension and fatigue of eyes, quick judgment, decrease of accidents and disasters, pleasure in living and work, and improved work efficiency. Furthermore, it also has social effects because it helps organization and maintenance of cleanliness, facilitates management, and improves surrounding environment.

Existing studies on emotional reactions to colors focused on the correspondence between hue classifications based on basic color names and the basic classifications of emotion. However, hue is only one of the three properties of color (value, chroma, and hue) and to classify colors by hue is to overlook the other two properties (value and chroma). A recent study on cognitive psychology revealed that among the three properties of color, the 
emotional reaction to chroma was greater than the emotional reaction to hue. ${ }^{24)}$ This study analyzed the characteristics of emotional reactions to chromatic variations and examined the cases of object colors which are perceived through reflection from objects - case of surface characteristics excluded (paper) and perceived (fiber) - and the cases of luminescent colors perceived from a monitor. The design of color stimulations according to tone is based on the relative vividness in a color group and on the understanding of the cognitive quality rather than the physical quality of colors. ${ }^{25)}$ This study experimented on three tones, dark, vivid, and light tones under natural light. Among the three color groups (red, blue, and yellow), the vivid tone showed higher values in the two dimensions of pleasure and arousal than the dark and light tones did. The author also pointed out that chromatic variations in color design can provide the variation of emotional reactions desired by the design. ${ }^{26)}$ In the information processing science, a collaborative filtering study on the recommendation of harmonious colors was conducted for more efficient management and utilization of color data. ${ }^{27)}$ However, it was about a prediction system for personal preferences and it is difficult to apply the result to industries.

The background colors of work sites and the application of colors to worker protection are also being studied in architectural engineering in recent times. A study on colors regarding the accidents and their prevention in construction sites $^{28)}$ showed that color schemes are not sufficiently applied to construction sites and many accidents were caused by no distinction of working clothes and protective gear from the environment of the work sites. This study claimed that to improve accident prevention of construction sites, the colors of working clothes should be changed for recognition of workers and for psychological safety. Furthermore, the authors stated that blue line colors were appropriate for the construction of a safety net that can give tension to workers and call their attention through the harmony of different colors. They suggested a change of color scheme from yellow line to blue line and from green yellow line to yellow red line. ${ }^{29)}$ Thus, color conditioning in work sites is critical for safety and the implementation of safety through color arrangement of working clothes which protect workers at the very first is needed in the integrated environmental color planning of a work site.

\section{Method and Details of Study}

The study method consisted of literature research, empirical research, and evaluation research. The literature research performed theoretical examination about colors, industrial safety, and visibility. Three actual outdoor work sites in the machine industry were chosen and pictures were taken at $20-30 \mathrm{~m}$ from workers. The background colors of the work environment of each work site and the colors of the working clothes that were actually worn were analyzed through color values measured with a color-difference meter(CR-400). For color differences, the colors of three random places in the analyzed parts were extracted and their averages were used.

For this experiment, 5PB line in the Munsell hue circle was chosen for the top color and the $5 \mathrm{~B}$ line for the bottom color for similar color arrangement. According to the Munsell color selections, the closest colors were chosen using 
the PANTONE@ color chip by the visual sensation method of two persons, researcher and research assistant. The chosen PANTONE color numbers were 19-3847 TPX and 19-3528 TPX. The colors of working clothes for each work site were varied with the Texpro Design CAD program. The reason for using the PANTONE color chip was that it can be easily transformed to this CAD program and the color values can be easily obtained by converting the by the Munsell color conversion program.

After applying the color arrangement, the color differences after conversion of the background color values of the same work environment and the color arrangement for working clothes were derived, and the differences in value, chroma, and tone which are related to visibility were checked. These results were summarized in a table, color triangle, hume circle, NCS, and PCCS tone.

The visibility was evaluated by nine experts: three fashion designers (with master's and doctor's degree), three industrial engineering experts (with master's and doctor's degree), and safety managers of machine industry sites (with over 10 year career). For the evaluation, the 5-point Likert scale about the changes on computer monitors was used: Not at all (1 point), False (2 points), Average (3 points), True (4 points), and Very True (5 points). The evaluation items were the appropriateness and harmony of visibility and the harmony of top and bottom color arrangement of the working clothes of different color arrangements in working environment for each case of the three work sites.

\section{Results and Discussion}

\section{Analysis of the working environment and the colors of working clothes in machine work sites}

The case of work site A was found to be very turbid colors with a little unbalance of green and blue lines because top and bottom colors have similar RGB values. Regarding the $L * a * b *$ value (hue and chroma), the chroma value $b *$ of the top and the chroma value $a * b *$ of the bottoms are all negative $(-)$. The working clothes of work site $B$ were similar. They were more biased to blue line than case $A$, but there was no clear difference in vividness and the colors of case $B$ were also turbid. In the case of $\mathrm{C}$, the colors were closer to red line, yellow line, and blue line compared to $\mathrm{A}$ and $\mathrm{B}$, but the differences were not large. For the value coefficient $L *$, case $C$ showed a highest value for top and $B$ showed the highest value for bottoms $\langle$ Table 1$\rangle$.

The analysis of working clothes through Munsell hume circle found that the colors of working clothes were mainly $\mathrm{PB}$ line and only the top of case $C$ was $Y R$ line.

\section{Comparison of colors and color arrangement of top and bottoms between prior to and after change of the working clothes}

The results of the comparison between the current color arrangement and the color arrangement after simulation for change of the color arrangement of working clothes are described below. In the case of work site $A$, the working clothes consisted of 5.29 PB line for top and 7.87 PB for bottoms, which were very similar and belong to the same color group. The changed working clothes used similar color arrangement 
$<$ Table $1>R G B, L * a * b *$, HVC, tone color value of industrial site

\begin{tabular}{|c|c|c|c|c|c|c|c|c|c|c|c|c|c|}
\hline \multirow{2}{*}{ Site } & \multirow{2}{*}{\multicolumn{2}{|c|}{ Contents }} & \multicolumn{9}{|c|}{ Color value } & \multirow{3}{*}{ Color } & \multirow{3}{*}{$\frac{\text { PCCS }}{\operatorname{ltg}}$} \\
\hline & & & \multirow{2}{*}{$\frac{H}{1.87 Y}$} & \multirow{2}{*}{\begin{tabular}{|c|}
$V$ \\
7.85 \\
\end{tabular}} & \multirow{2}{*}{\begin{tabular}{|c|}
$C$ \\
1.38 \\
\end{tabular}} & \multirow{2}{*}{\begin{tabular}{|c|}
$R$ \\
205
\end{tabular}} & \multirow{2}{*}{\begin{tabular}{c|}
$G$ \\
196
\end{tabular}} & \multirow{2}{*}{\begin{tabular}{|c|}
$B$ \\
178
\end{tabular}} & \multirow{2}{*}{\begin{tabular}{|c|}
$L *$ \\
79.90 \\
\end{tabular}} & \multirow{2}{*}{\begin{tabular}{|c|}
$a *$ \\
0.07
\end{tabular}} & \multirow{2}{*}{$\frac{b *}{10.06}$} & & \\
\hline \multirow{7}{*}{$A$} & \multirow{5}{*}{$\begin{array}{c}\text { Industrial } \\
\text { Environment }\end{array}$} & Ground & & & & & & & & & & & \\
\hline & & $\begin{array}{c}\text { Steel } \\
\text { structure }\end{array}$ & $0.51 \mathrm{~B}$ & 4.20 & 1.37 & 90 & 105 & 107 & 43.32 & -5.39 & -3.16 & & g \\
\hline & & Materials & $9.01 Y R$ & 5.41 & 1.02 & 140 & 131 & 122 & 55.72 & 1.79 & 6.22 & & g \\
\hline & & Tent & $1.79 P$ & 1.93 & 0.46 & 52 & 51 & 54 & 19.84 & 1.36 & -1.96 & & $\mathrm{dkg}$ \\
\hline & & container & $5.26 \mathrm{GY}$ & 5.90 & 1.72 & 141 & 148 & 126 & 60.70 & -6.76 & 10.97 & & $\operatorname{ltg}$ \\
\hline & \multirow{2}{*}{$\begin{array}{l}\text { Working } \\
\text { Clothes }\end{array}$} & Top & 5.29PB & 3.10 & 1.80 & 71 & 76 & 89 & 31.76 & 1.14 & -8.85 & & $\mathrm{dkg}$ \\
\hline & & Bottom & 7.87PB & 5.26 & 2.56 & 110 & 132 & 143 & 54.21 & -5.49 & -8.69 & & g \\
\hline \multirow{7}{*}{$B$} & \multirow{5}{*}{$\begin{array}{c}\text { Industrial } \\
\text { Environment }\end{array}$} & Ground & 9.69YR & 6.63 & 1.06 & 172 & 163 & 152 & 68 & 1.33 & 6.9 & & $\mathrm{Itg}$ \\
\hline & & Steel barrel A & 6.61YR & 3.30 & 2.66 & 99 & 76 & 60 & 33.86 & 7.66 & 14.29 & & $\mathrm{dkg}$ \\
\hline & & Shadow & $3.42 \mathrm{~PB}$ & 5.74 & 2.28 & 132 & 142 & 155 & 59.10 & -0.88 & -8.19 & & $\operatorname{ltg}$ \\
\hline & & Steel barrel B & 4.97RP & 1.51 & 0.26 & 45 & 43 & 44 & 15.7 & 1.34 & -0.44 & & $\mathrm{dkg}$ \\
\hline & & \begin{tabular}{|c|} 
Steel \\
\end{tabular} & $0.72 \mathrm{G}$ & 2.28 & 3.14 & 43 & 63 & 47 & 23.34 & -13.19 & 8.15 & & $\mathrm{dkg}$ \\
\hline & \multirow{2}{*}{$\begin{array}{l}\text { Working } \\
\text { Clothes }\end{array}$} & Top & $7.25 \mathrm{~PB}$ & 3.02 & 3.09 & 70 & 73 & 96 & 30.97 & 4.94 & -14.78 & & $\mathrm{dkg}$ \\
\hline & & Bottom & $1.52 \mathrm{~PB}$ & 6.91 & 4.16 & 147 & 175 & 198 & 70.67 & -4.46 & -14.76 & & s \\
\hline \multirow{7}{*}{ C } & \multirow{5}{*}{$\begin{array}{c}\text { Industrial } \\
\text { Environment }\end{array}$} & Barrel & $2.02 R$ & 6.02 & 0.49 & 152 & 147 & 147 & 61.87 & 1.85 & 0.66 & & $\lg$ \\
\hline & & Hose & $5.43 \mathrm{P}$ & 4.41 & 0.92 & 110 & 106 & 112 & 45.48 & 2.91 & -2.90 & & $g$ \\
\hline & & $\begin{array}{c}\text { Steel } \\
\text { structure A }\end{array}$ & $3.76 \mathrm{Y}$ & 8.53 & 11.04 & 254 & 212 & 57 & 86.50 & -0.44 & 77.31 & & $b$ \\
\hline & & $\begin{array}{c}\text { Steel } \\
\text { structure B }\end{array}$ & $4.90 \mathrm{~PB}$ & 4.04 & 5.55 & 78 & 99 & 135 & 41.64 & 2.09 & -23.21 & & $d$ \\
\hline & & $\begin{array}{c}\text { Steel } \\
\text { structure C }\end{array}$ & $1.12 \mathrm{GY}$ & 7.51 & 2.44 & 189 & 190 & 153 & 76.55 & -6.57 & 18.59 & & $\lg$ \\
\hline & \multirow{2}{*}{$\begin{array}{l}\text { Working } \\
\text { Clothes }\end{array}$} & Top & $5.87 Y R$ & 5.77 & 2.13 & 159 & 138 & 123 & 59.43 & 5.49 & 11.16 & & $\lg$ \\
\hline & & Bottom & 5.64PB & 2.13 & 2.66 & 49 & 55 & 72 & 21.80 & 2.47 & -12.37 & & $\mathrm{dkg}$ \\
\hline
\end{tabular}

with different colors from the previous color arrangement.

In the case of work site $B$, the previous color arrangement of working clothes used the similar colors of the PB line and there were no large differences between prior to and after change. In the case of work site $\mathrm{C}$, the previous color arrangement corresponded to opposite color arrangement of $\mathrm{YR}$ and $\mathrm{PB}$ lines, but it was changed to similar color arrangement of the $\mathrm{PB}$ line $\langle$ Table 2>.

After simulation of the working clothes color arrangement, they were all adjusted to similar color arrangement, and work site C underwent 
the greatest change of color arrangement.

$<$ Table 3> shows a comparison of color pallette between prior to and after working clothes simulation for each work site, and a color triangle through color analysis by NCS measurement. For the work site $A$, the top was S6010-R90B with the black color level of 60 and the chromatic color level of 10 , and it was dark. the color was R908 which is a blue line color with 90 blue and 10 red. The bottoms were purple blue line (with a little green) of S3020 - B10G with the black color level of 30 and the chromatic color level of 20. After simulation, the bottoms were S2060-B with lower black color level of 20 and the higher chromatic color level of 60 . The color was blue.

The working clothes of work site B were also changed to blue with a higher chromatic color level. In the case of work site $\mathrm{C}$, the black color level of top was changed from 40 to 50 , which seems to be a little high, but it was the result of a similar color arrangement from yellow line to blue line. For the simulation of bottom color, the black color level was lowered and the color value was changed from $\mathrm{N}$ which is an achromatic value to blue line<Table $3>$. Consequently, the black color level was lowered and the chromatic color rate was increased from those of the previous working clothes through simulation in general to achieve vividness and the colors were changed to the blue line.

\section{Comparison of differences in hue, value, chroma, and tone of top/bottoms after change}

The site picture analysis and the results of simulation found that the differences in top and bottom colors in work site $A$ were less than about 4.0 and 3.5 , respectively, but there was no large difference in value. The chroma showed the greatest differences after change: about 5.8

$<$ Table 2> Color \& color arrangement change before \& after of top/bottom of working clothes

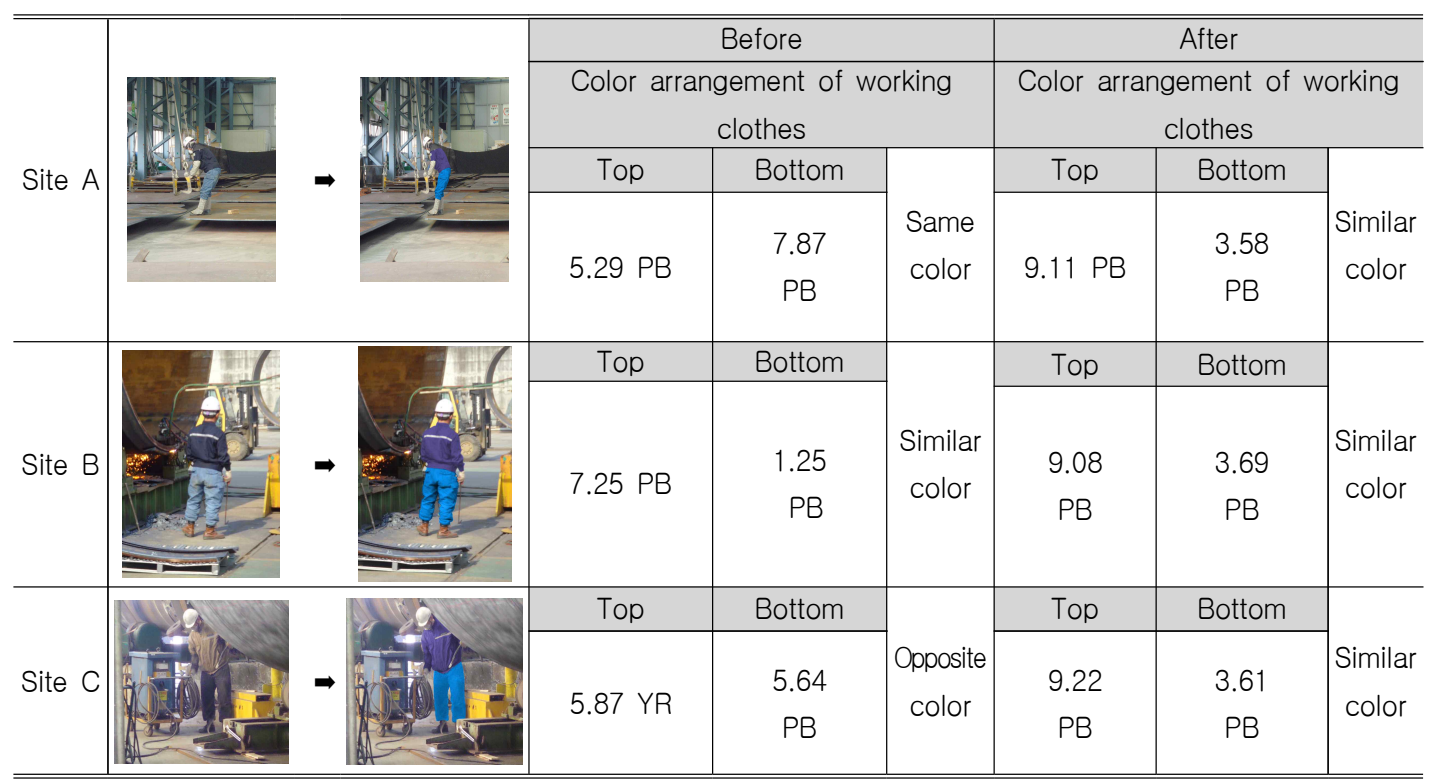


$<$ Table 3> NCS variation change before \& After of working clothes

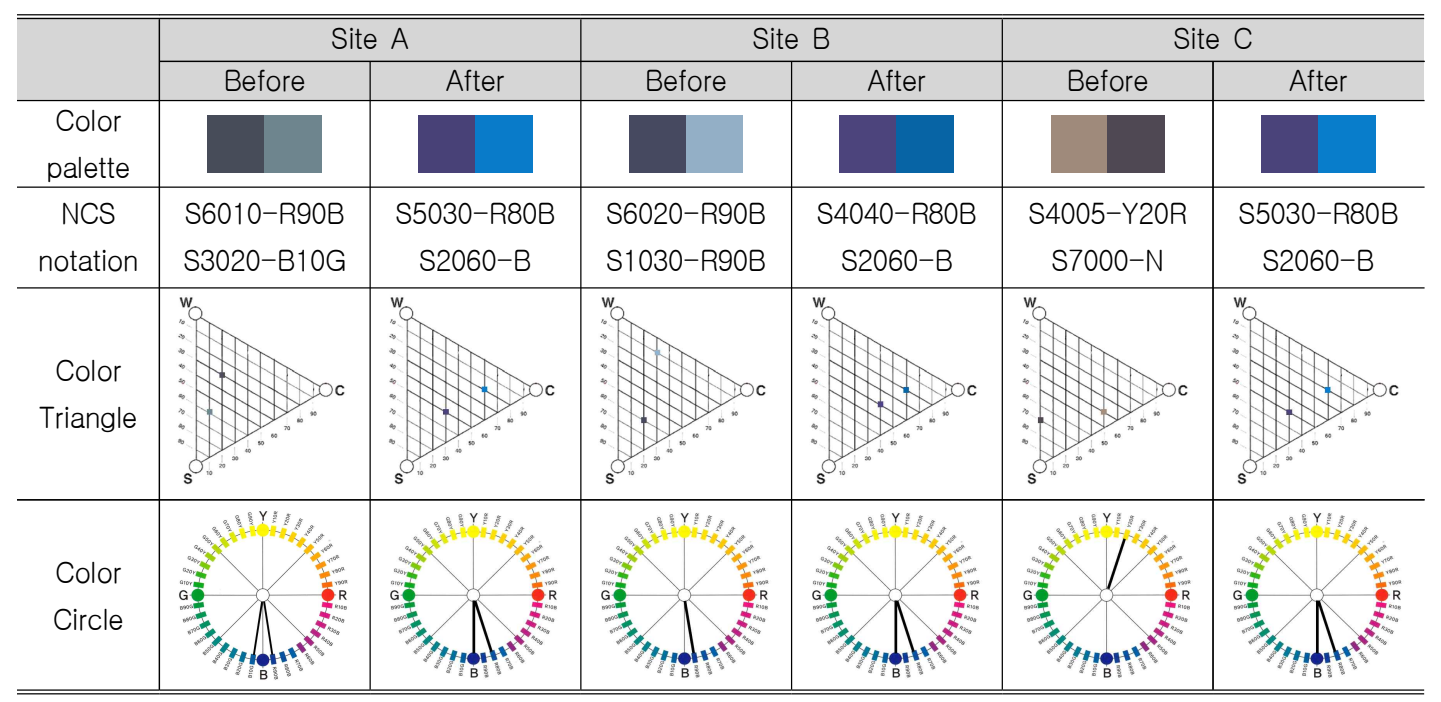

for top and about 9.5 for bottoms. For tone, it changed from $\mathrm{dkg}$ to $\mathrm{dp}$ and from $\mathrm{g}$ to $\mathrm{v}$. The work environment colors which are background colors were mainly $Y, Y R$, and GY lines. value ranged from vary low value (1.93) to middle or higher value (7.85). The differences of value and chroma were very large. Because the work environment color had a low chroma of 1.72 , the chroma difference after change of color arrangement was 10.0 or higher.

The background colors of work site $B$ were $Y R, P B, R P$, and G. Because the colors of working clothes were fixed to the PB line, there was no big difference in value between background and working clothes, whereas the chroma difference was increased to 9.0 or greater. For tones, in the work environment of grayish tone, the working clothes were changed to $\mathrm{dp}$ and $\mathrm{v}$ tones.

In work site $C$, the work environment colors were $R, P, Y, P B$, and $G Y$ lines and the working clothes colors were $Y R$ and $P B$ lines which were changed to the PB line. The value of the work environment was middle value group as was the working clothes, but the latter was a little low. For chroma, however, they were all low except for one iron structure (11.0), and the chromas of working clothes were 7.80 and 10.3 compared to the low chromas before change (2.13 and 2.66). For tones, the working clothes were also grayish tone as were the background colors. After similar color arrangement, the working clothes were changed to darker tones $\mathrm{dkg}$ and $\mathrm{dk}\langle$ Table 4$\rangle$. These results can be easily understood in a graphic presentation <Figure 1>.

\section{Evaluation of visibility for the changed color arrangement of working clothes}

The results of simulation that changed chroma around the similar color arrangement of purple blue (PB) through color harmony theory were evaluated around the items related to safety in the work sites. The evaluations were carried out by nine experts: three fashion design experts (with 
$<$ Table 4> Comparison of differences in hue, value, chroma, and tone of top/bottoms after change

\begin{tabular}{|c|c|c|c|c|c|c|c|c|c|c|c|}
\hline \multirow{2}{*}{ Site } & \multirow{2}{*}{ clothes } & \multicolumn{2}{|c|}{$\mathrm{H}$} & \multicolumn{3}{|c|}{ V } & \multicolumn{3}{|c|}{ C } & \multicolumn{2}{|c|}{ Tone } \\
\hline & & Before & After & Before & After & Difference & Before & After & Difference & Before & After \\
\hline A & \multirow{3}{*}{ Top } & $5.29 \mathrm{~PB}$ & $9.11 \mathrm{~PB}$ & 3.10 & 7.66 & +4.56 & 1.80 & 7.66 & +5.86 & $\mathrm{dkg}$ & $d p$ \\
\hline$B$ & & 7.25PB & 9.08PB & 3.02 & 2.92 & -0.1 & 3.09 & 7.57 & +4.48 & $\mathrm{dkg}$ & $s$ \\
\hline$C$ & & 5.87YR & $9.22 \mathrm{~PB}$ & 5.77 & 3.07 & -2.7 & 2.13 & 7.80 & +5.67 & $\lg$ & dk \\
\hline A & \multirow{3}{*}{ Bottom } & 7.87PB & $3.58 \mathrm{~PB}$ & 5.26 & 4.95 & -0.31 & 2.56 & 12.06 & +9.50 & g & v \\
\hline$B$ & & $1.52 \mathrm{~PB}$ & 3.69PB & 6.91 & 4.88 & -2.02 & 4.16 & 12.05 & +7.89 & s & v \\
\hline$C$ & & 5.64PB & $3.61 \mathrm{~PB}$ & 2.13 & 3.98 & +1.85 & 2.66 & 10.37 & +7.71 & $\mathrm{dkg}$ & $\mathrm{dp}$ \\
\hline
\end{tabular}
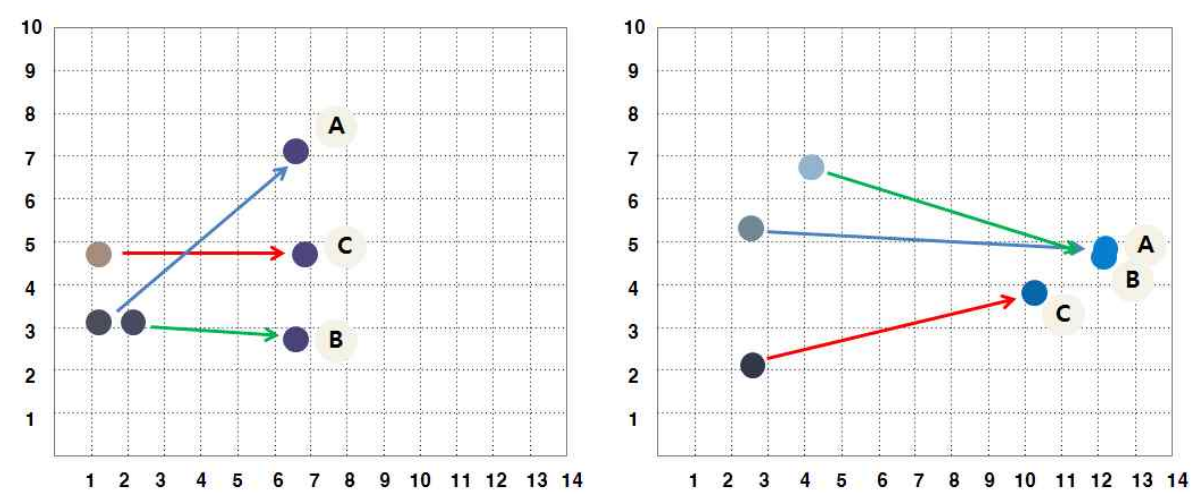

<Figure 1> Value, chroma of top(left)/bottoms(right) change before \& after of working clothes

master's and doctor's degree), three industrial engineering experts (ith master's and doctor's degree), and safety managers of machine industry sites (with over 10 year career). For the evaluation, the 5-point Likert scale about the changes on computer monitors was used: Not at all (1 point), False (2 points), Average (3 points), True (4 points), and Very True (5 points). The evaluation items were the appropriateness and harmony of visibility and the harmony of top and bottom color arrangement of the working clothes of different color arrangements in working environment for each case of the three work sites.

As a result, for "conspicuousness (improved attractiveness)", all work sites $A, B$, and $C$ received very high scores of 4.22, 4.22, and 4.45, respectively. For "good vision from a distance (improved clear vision)' they also received high scores of $4.33,4.11$, and 4.56 , respectively. The scores for "good distinction from surrounding (improved visibility)" were also high at 4.22, 4.22, and 4.33, respectively. For "helpful for improvement of safety", the scores were a little lower than the other three items, but they were generally high at 4.11, 3.78, and 3.89, respectively<Table $5>$. This result can be understood as owning to the attempt to change the colors of working clothes excluding the fluorescent and safety bands and safety vests. For the question "Would it help site management?", the scores were 4.11, 4.22, and 
$\langle$ Table 5$\rangle$ Visibility evaluation results following the change of color arrangement for working clothes

\begin{tabular}{|c|c|c|c|}
\hline Questions & Site A & Site B & Site C \\
\hline $\begin{array}{l}\text { The color arrangement of working clothes after change is more } \\
\text { conspicuous in the given work environment than that before change } \\
\text { (improved attractiveness). }\end{array}$ & 4.22 & 4.22 & 4.45 \\
\hline $\begin{array}{l}\text { The color arrangement of working clothes after change is more visible } \\
\text { from a distance than that before change (improved clear vision). }\end{array}$ & 4.33 & 4.11 & 4.56 \\
\hline $\begin{array}{l}\text { In general, the color arrangement of working clothes after change } \\
\text { better distinguishes workers from the surrounding in the given work } \\
\text { environment than that before change (improved visibility). }\end{array}$ & 4.22 & 4.22 & 4.33 \\
\hline $\begin{array}{l}\text { The color arrangement of working clothes after change will help } \\
\text { improve safety in the given work environment compared to that before } \\
\text { change (improved safety). }\end{array}$ & 4.11 & 3.78 & 3.89 \\
\hline $\begin{array}{l}\text { The color arrangement of working clothes after change will help site } \\
\text { management in the given work environment compared to that before } \\
\text { change (improved convenience of site management). }\end{array}$ & 4.11 & 4.22 & 4.20 \\
\hline
\end{tabular}

4.20, respectively, indicating higher visibility and safety compared to the existing working clothes. The scores for improved attractiveness and visibility were the highest in work site $C$ and the reason for this seems to be that the colors of the existing working clothes were similar to those of the work site.

\section{Conclusions}

In this study, pictures of the actual work environment of machine industry sites were taken to investigate the background colors of work sites and the similar color arrangement was simulated for the current PB-line working clothes to objectively find a method to improve visibility. The case of work site A was found to be very turbid colors with a little unbalance of green and blue lines because top and bottom colors have similar RGB values.

After simulation of the working clothes color arrangement, they were all adjusted to similar color arrangement, and work site C underwent the greatest change of color arrangement. After similar color arrangement, the working clothes were changed to darker tones $\mathrm{dkg}$ and $\mathrm{dk}$.

As a result, it was found that between value and chroma which affect visibility, color arrangement based on differences in chroma could be a greater influence than color arrangement based on differences in value. As a result, for "conspicuousness (improved attractiveness)", all work sites A, B, and C received very high scores of 4.22, 4.22, and 4.45, respectively. For "good vision from a distance (improved clear vision)' they also received high scores of 4.33, 4.11, and 4.56, respectively. The scores for "good distinction from surrounding (improved visibility)" were also high at 4.22, 4.22, and 4.33, respectively. For "helpful for improvement of safety", the scores were a little lower than the other three items, but they were generally high at 4.11, 3.78, and 
3.89, respectively.

The result of this study is similar to the finding of a previous study that among the relevant color characteristics, visibility is identical to legibility for good perception of forms and differences in chroma affect visibility. It also seems to be related to the finding of a previous study that emotional reactions are greater by difference in chroma than difference in value among the properties of color. These results suggested that as differences in value and chroma which affect visibility as presented in the color theory, chroma could be better utilized than other factors for achieving visibility through the colors of working clothes in the backgrounds of machine industry sites.

Therefore, for worker protection for industrial safety, color conditioning of working clothes considering the color arrangement of working clothes based on chroma for the PB line will bring about positive results. The opposite or contrast colors that affect legibility can cause the fatigue of eyes, and could be used for accessories such as working hats and safety bands.

This study has limitations to its interpretation in that specific sites in the machine industry were chosen and the condition of similar color arrangement around the PB line was used. However, this study can contribute to the standardization of safe working clothes colors through the acquisition of many data on color arrangement research and the systematization and quantification of such data. In the future, it is anticipated that studies on value color arrangement and chroma color arrangement will be conducted to establish better standards for safe working clothes color arrangements.

\section{Reference}

1) Yoon Yonggu(2004), "A Study for Human -Error Prevention of Chemical Plant Safety Accident", Journal of Korea Safety Management \& Science, 6(2), p.8.

2) Ibid., p.5.

3) Kim Seongsook, Kim Heeeun(2008), "The Evaluation of Functionality with MaterialImproved Working Uniform of Construction Field", Journal of the Korean Society of Clothing Industry, 10(2), pp.228-235.

4) Bae Hyunsook(2010), "The Analysis on the Work Environment and Working Clothes Wearing Conditions of Shipyard Painters", Journal of the Korean Society of Clothing and Textiles, 34(3), pp.518-528.

5) Park Ginah, Park Hyewon, Bae Hyunsook (2012), "The Analysis of the Painting Work Clothes Clothing Comfort and Wearer Mobility Considering the Work Environment in the Machine and Shipbuilding Industries", Journal of Fashion Business, 16(3), pp.13 -31 .

6) Kim Sangho, Park Kwanseok(2004), "A Study on Color Associations of the Korean for Color Coding of Process Control Information", Journal of Korea Safety Management \& Science, 6(1), p.188.

7) Yoon Hyerim(2008), Color Perception Theory and System Theory, Gookje, pp.154-155.

8) Park Hyewon(2010), Development and Color Evaluation of Working Clothes Designs for Intergrated Environment Color Planning in Machinery Industry Sites, Journal of Fashion Business, 14(6), pp.53-69.

9) Park Hyewon(2010), "Case Study Color Analysis of Work Clothes and Industrial Factories for Coordinating Environment Planning - Focus on Shipbuilding Companies", 
Journal of the Korean Society of Clothing and Textiles, 34(3), pp.540-552.

10) Park Gina, Park Hyewon, Bae Hyunsook (2011), "The Analysis on Work Clothes' Clothing Comfort and Wearer Mobility of Welding and Grinding and Workers in the Machine and Shipbuilding Industries", Journal of Fashion Business, 15(2), p.146.

11) Park Hyewon, Yang Junghee(2012), "Color Arrangement Evaluation on Working Clothes for Safety and Integrated Environment Harmony in Machinery Industry Fields", Journal of Fashion Business, 16(5), pp.207-219.

12) Yi Juneseong, Kim Yongwoo, Kim Kiaeng, Koo Bonsang(2012), "A Suggested Color Scheme for Reducing Perception-related Accidents on Construction Work Sites", Accident Analysis and Prevention, 48, p.189.

13) Yoon Hyerim(2008), Color Perception Theory and System Theory, Gookje, p.3.

14) Faber Birren(2008), Effect of color, Kim Jin han(translator)(2008), Sigongsa, p.168.

15) Kim Gilhong et al.(2001), Evironment Color Planning Theory, Ewha Women's University Color Design Institute. p.46.

16) Yoon Hyerim(2007), A Color Psychology Marketing and Arrangement Theory, Gookje, p.48.

17) Ibid., p.48.
18) Retrieved 2012.11.22, from www.engineersinternational.com/29-9-29.php

19) Yoon Hyerim(2007), op.cit., p.49.

20) Retrieved 2012.11.23, from http://terms. naver. com/entry. $n$ hn? cid $=470 \&$ docld $=509655$ \&categoryld $=1138$

21) Retrieved 2012.11.22, from www.orosha. org/pdf/pubs/fact_sheets/fs42.pdf

22) Retrieved 2012.7.17, from http://www.ehow. com/about_6398021_osha-safety-color-code s.html

23) Retrieved 2012.7.17, from http://www.ehow. com/list_7419984_ansi-rules-safety-vests.htl $\mathrm{m}$

24) Retrieved 2012.11.23, from http://dong397. blog.me/40096774030

25) Suk Hyeonjeong(2007), "A Study on a Correlation between Color Chroma and Appetitive Motivation Across Media", Korea design research, Spring Conference, p.188.

26) Ibid., p.188.

27) Ibid., p.189.

28) Park Eunyoung, Park Youngho(2011), "Assumption based on Recommending harmonious Colors", Korea Information \& Processing Society, Spring Conference, p. 1478

29) Yi Juneseong, Kim Yongwoo, Kim Kiaeng, Koo Bonsang(2012), op.cit., p.189.

Received (Mar. 6, 2013)

Revised (Apr. 1, 2013)

Accepted (Apr. 5, 2013) 